ISSN 2236-0859

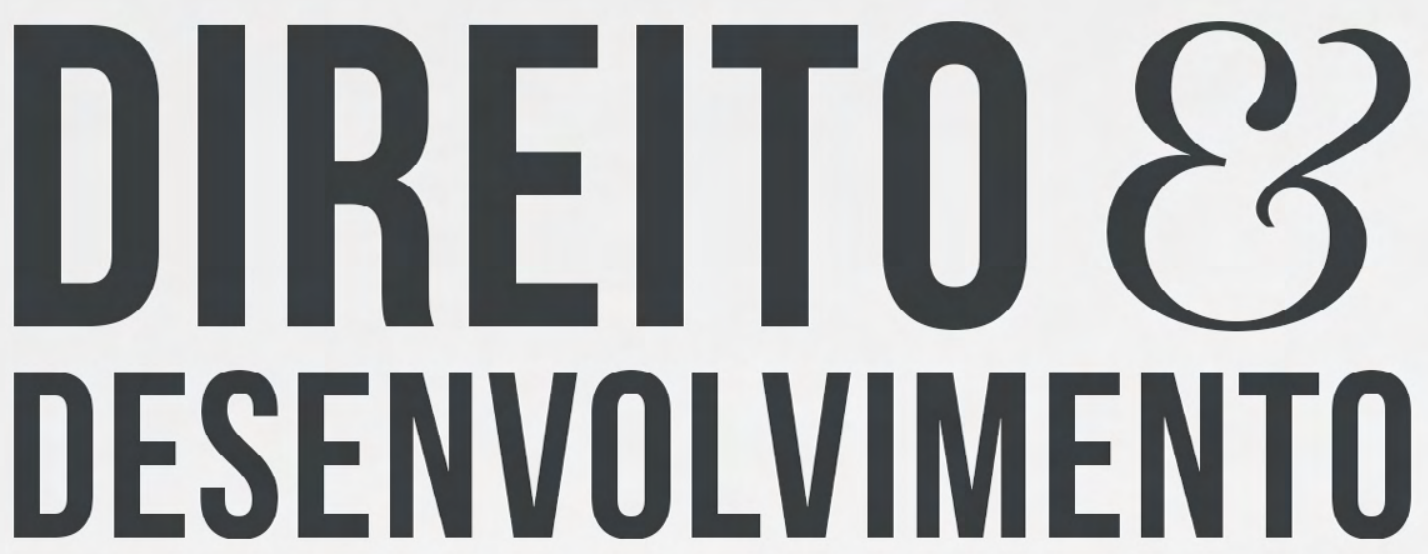

REVISTA DO PROGRAMA DE PÓS-GRADUAÇ̃̃O EM DIREITO MESTRADO EM DIREITO E DESENVOLVIMENTO SUSTENTÁVEL

SOCIEDADE DE CONSUMOE O CONSUMIISMO: IMPLICAÇÕES EXISTENCIAIS NA DIMENSÃO DA SUSTENTABLLIDADE

JOSEMAR SIDINEI SOARES

MARIA CLÁUDIA DA SILVA ANTUNES DE SOUZA 


\title{
SOCIEDADE DE CONSUMO E O CONSUMISMO: IMPLICAÇÕES EXISTENCIAIS NA DIMENSÃO DA SUSTENTABILIDADE
}

\section{CONSUMER SOCIETY AND CONSUMMISM: EXISTENTIAL IMPLICATIONS IN THE DIMENSION OF SUSTAINABILITY}

Recebido: 31/07/2018

Aprovado: 17/09/2018

Josemar Sidinei Soares*

Maria Cláudia da Silva Antunes de Souza**

\begin{abstract}
RESUMO: A pesquisa tem por objeto a análise da sociedade de consumo e as consequências na vida humana, a partir de uma análise histórica e doutrinária referente à temática, sobretudo no que se refere à questão da sustentabilidade. Assim, o objetivo da pesquisa é, analisar a sociedade de consumo, seus hábitos e desejos e, quais as consequências na vida humana, demonstrando que este assunto decorre diretamente de atitudes existenciais. A relação entre consumismo e sustentabilidade não pode ser aperfeiçoada somente por meio de políticas públicas e diretrizes jurídicas, mas a partir da disseminação de uma nova cultura de responsabilização humana diante desi, dosambientes nos quais interage edo próprio planeta. Políticas de sustentabilidade tendema sofrer dificuldade para serem implementadas com êxito enquanto a cultura contemporânea ainda enfatizar excessivamente o vínculo entre Felicidade e Consumerismo. Quanto à metodologia, foi utilizada a base lógica indutiva por meio da pesquisa bibliográfica.
\end{abstract}

Palavras-chave: Sociedade de Consumo. Consumerismo. Felicidade. Existência. Sustentabilidade.

ABSTRACT: The aim of this research is to analyze the consumer society and the consequences in human life, based on a historical and doctrinal analysis related to the theme, especially with regard to the question of sustainability. Thus, the purpose of the research is to analyze consumer society, its habits and desires, and what the consequences in human life, demonstrating that this issue stems directly from existential attitudes. The relationship between consumerism and sustainability can not be improved only through public policies and legal guidelines, but from the dissemination of a new culture of human responsibility before the self, the environments in which it interacts and the planet itself. Sustainability policies tend to be difficult to implement successfully while contemporary culture still overemphasizes the link between happiness and consumerism. As for the methodology, the inductive logic base was used through bibliographic research.

Keywords: Consumer Society. Consumerism. Happiness. Existence. Sustainability.

\section{INTRODUÇÃO}

A sociedade de consumo é notavelmente calcada no crescimento do consumismo na sociedade para manter a circulação de capitais e garantir a geração de lucro. Entende-se por sociedade de consumo a era contemporânea do capitalismo em que o crescimento econômico e a geração de lucro e riqueza encontram-se predominantemente pautados no crescimento da * Doutor em Filofosia - Universidade Federal do Rio Grande do Sul. Mestre em Educação - UFSM. Mestre em Ciência Jurídica UNIVALI. Professor no Programa de Pós-Graduação Stricto Sensu em Ciência Jurídica - UNIVALI. E-mail: jsoares@univali.br ** Doutora e Mestre em Derecho Ambiental y Sostenibilidad - Universidade de Alicante, Espanha. Mestre em Ciência Jurídica UNIVALI. Professora no Programa de Pós-Graduação Stricto Sensu em Ciência Jurídica - UNIVALI. E-mail: mclaudia@univali.br 
atividade comercial e, consequentemente, do consumo. Para manter esse desenvolvimento, incentiva-se o consumo de várias maneiras, principalmente a fetichização das mercadorias e o crescimento dos meios publicitários.

O desenvolvimento da sociedade de consumo ocorreu de forma mais completa a partir da expansão da atividade industrial ao longo dos séculos XVIII, XIX e XX. As frequentes invenções e modernizações produtivas provocaram um crescimento sem igual no nível de consumo, bem como na difusão cada vez mais ampla da publicidade no meio de vida da população, com a divulgação dos mais diversos produtos, sendo eles úteis ou não.

Na era da pós-modernidade, pensar o planeta requer uma visão para além dos limites territoriais e geográficos estatais, isto porque a Sustentabilidade deve ser abordada em uma perspectiva global, considerando que os benefícios e riscos em matéria ambiental são repartidos solidariamente por todo o mundo, todos desfrutam da casa comum, a terra (BOFF, 2013).

Diante deste panorama, a relevância social e científica desta pesquisa justifica-se na necessidade refletir sobre a sociedade de consumo e suas consequências na vida humana. Nesta senda, obteve-se com a presente pesquisa, a análise da sociedade de consumo, consumismo e seus impactos aos meio ambiente e no planeta. O Objetivo é analisar a sociedade de consumo e as consequências na vida humana, a partir de uma análise histórica e doutrinária referente à temática, demonstrando que o vínculo cultural estabelecido entre as ideias de Felicidade e Consumerismo coloca em risco a própria possibilidade de uma sociedade mais sustentável..

A Metodologia escolhida para a elaboração deste Artigo considerou as fases da Pesquisa Científica (PASOLD, 2018). Para se desenvolver a base lógica deste artigo na fase de investigação, optou-se pela adoção do Método Indutivo. As técnicas de pesquisa acionadas para se cumprir com a finalidade proposta pelo método eleito são a Pesquisa Documental, histórica e Bibliográfica, a Categoria e o Conceito Operacional. As adoções dessas últimas ferramentas são necessárias para se estabelecer, com clareza necessária, o Acordo Semântico entre os escritores e o(s) leitor (es) a fim de se estabelecer, minimamente, quais são os pressupostos teóricos que conduzem o desenvolvimento, inclusive ideológico, deste estudo.

\section{SOCIEDADE E VIDA DE CONSUMO}

Vive-se hoje um período definido por muitos como pós-modernidade, um termo de difícil definição precisa, mas que no meio de diversas definições e características apresentadas por diferentes autores (inclusive por alguns que não usam o termo, mas também realizam análises e críticas à cultura contemporânea), um dos elementos que frequentemente aparece como central é o consumismo, fazendo com que alguns autores definam a atual sociedade como sociedade de consumo.

Para definir as condições da pós-modernidade e discutir as transformações do mundo moderno nos últimos tempos, o sociólogo sempre preferiu usar o termo "modernidade líquida", por considerar "pós-modernidade" um conceito ideológico.

Bauman (2001) escolheo "líquido" como metáfora para ilustrar o estado dessas mudanças: facilmente adaptáveis, fáceis de serem moldadas e capazes de manter suas propriedades originais. As formas de vida moderna, segundo ele, se assemelham pela vulnerabilidade e fluidez, incapazes de manter a mesma identidade por muito tempo, o que reforça esse estado temporário das relações sociais.

Há 100 anos, ser moderno significava buscar um ponto de perfeição e hoje representa o progresso constante, sem um resultado final único prestes a ser conquistado. 
Jean-François Lyotard (1998) afirma que a pós-modernidade tem como motor uma busca desenfreada pelo progresso tecnológico e a propagação de uma ideologia do consumismo constante. $\mathrm{O}$ ator destaca que $\mathrm{o}$ avanço da tecnologia vem demonstrando que também a ciência não difere muito de mais uma forma de organizar, estocar e distribuir informações.

A ciência foi, e ainda, é em grande parte a bandeira dos intelectuais contra todo tipo de discurso religioso e filosófico, sobretudo o metafísico. A ciência moderna por muito tempo carregou aquela aura de conhecimento verdadeiro, seguro, capaz de ser aplicado com exatidão na vida em geral. No entanto, hoje a proposta principal da ciência é que ela apenas cumpra uma finalidade. O conhecimento hoje é produto, o indivíduo paga para receber uma informação específica.

De acordo com Livia Barbosa (2004, p. 13) em sua obra "Sociedade de consumo", "todo e qualquer ato de consumo é essencialmente cultural" e é por meio do consumo individual e local de cada homem que ocorrem alterações nas "forças globais de produção, circulação, inovação tecnológica e relações políticas”. No entanto, no mundo moderno o consumo se tornou o foco central da vida social. Práticas sociais, valores culturais, ideias, aspirações e identidades são definidas e orientadas em relação ao consumo ao invés de e para outras dimensões sociais como trabalho, cidadania e religião entre outros.

A sociedade atual, a sociedade do consumo, não surgiu após a Revolução Industrial e em virtude das invenções, facilidades e ofertas trazidos por ela. As grandes invenções tecnológicas teriam ocorrido simultaneamente e somente após uma mudança da relação do homem para com a necessidade e anseio de adquirir bens e produtos, Barbosa (2004, p. 13).

As principais invenções mecânicas da indústria de tecidos, cabeça de lança da industrialização, só apareceram a partir da década de 1780, embora a indústria de roupas já funcionasse a pleno vapor, fundada no trabalho externo ou doméstico dos artesãos, permanecendo com essa estrutura produtiva até a década de 1830 . O mesmo se refere à indústria de brinquedos, cujas inovações tecnológicas só vieram a afetá-la depois de plenamente estabelecida.

Diante disto, para Lívia Barbosa, "não foram essas invenções que criaram as condições materiais para as pessoas consumirem mais". Por isso, Zygmunt Bauman e Campbell acreditam que a fase de consumo exacerbado por que passa a sociedade moderna é caracterizada e tem origem na primazia da emoção e do desejo, o que faz com que se procure mais a gratificação destes do que a satisfação de necessidades. Além disso, há ainda o individualismo, que "atribui um valor extraordinário ao direito dos indivíduos de decidirem por si mesmos que bens e serviços desejam obter", Barbosa (2004, p. 49).

Dessa forma, a busca individualista pelo prazer de ter seus desejos satisfeitos gera total desequilíbrio na forma de vida do homem uma vez que "enquanto as necessidades de uma pessoa podem ser objetivamente estabelecidas, os [...] desejos podem ser identificados apenas subjetivamente", Barbosa (2004, p. 49). Sendo assim “o desejo dos consumidores é experimentar na vida real os prazeres vivenciados na imaginação, e cada novo produto é percebido como oferecendo uma possibilidade de realizar essa ambição".

E, como tal anseio grande parte das vezes não é alcançado, justamente em função da ideologia consumista, da dinâmica de mercado e da chamada democratização do consumo, a velocidade com que os estilos se alteram diminui a vida útil dos produtos fazendo com que um produto recém-adquirido se torne obsoleto, defasado e condenado à substituição sem ao menos ter perdido sua utilidade. Por conseguinte, é possível constatar que: 
[...] o espírito do consumismo moderno 'é tudo, menos materialista'. Se os consumidores desejassem realmente a posse material dos bens, se o prazer estivesse nela contido, a tendência seria a acumulação dos objetos, e não o descarte rápido das mercadorias e a busca por algo novo que possa despertar os mesmos mecanismos associativos, Barbosa (2004, p. 49).

O problema, então, encontra-se na formação e nos princípios do indivíduo. Atualmente, os compradores consomem apenas com o intuito de satisfazer seus desejos e o mercado sabe que "o preço que o potencial consumidor em busca de satisfação está preparado para pagar pelas mercadorias em oferta dependerá da credibilidade dessa promessa e da intensidade desses desejos", (BAUMAN, 2008, p. 18). E, como visto, o homem moderno é um ser individualista e as empresas especialistas em suscitar desejos que não existem ou existiriam no ser humano e afirmar podê-los satisfazer. Infelizmente, a reunião dessas circunstâncias faz o alto preço ser pago muito mais pelo meio ambiente do que pelo próprio sujeito.

O grande problema é que o homem do humanismo, aquele que vivia em harmonia com a natureza e com seus semelhantes, no seio de instituições cuja tutela não discutia, sobreviveu. Agora a necessidade se libertou da natureza, engendrando no homem uma paixão de possuir e um espírito de ambição que alimenta, por sua vez, a corrida ao poder. Transbordando os limites da necessidade natural, o interesse prolifera e contamina rapidamente todo o tecido social. As instituições que tinham tradicionalmente a tarefa de contê-lo se apresentam, contudo, como os instrumentos de uma vasta manipulação, tendendo a manter o poder dos mais fortes. (SOËTARD, 2010)

Além disso, essa perda do contato do homem com a natureza e o apoio das instituições na continuação da cultura do consumo fez com que os homens acreditassem ser senhores de si, independentes e alheios aos demais e ao ambiente a sua volta. É possível notar que não há real existência de "um universo no qual predomina a autonomia de escolha e a soberania do consumidor" como preconizam as propagandas e os vendedores.

O poder de escolha do indivíduo na esfera do consumo nas sociedades pós-tradicionais tem sido campo de debate sobre a sua real liberdade de escolha ou submissão a interesses econômicos maiores que se escondem por trás do marketing e da propaganda. Será o consumo uma arena de liberdade e escolha ou de manipulação e indução? Terá o consumidor efetivamente escolha? Ele é súdito ou soberano, ativo ou passivo, criativo ou determinado? (BARBOSA 2004, p. 35)

Em uma sociedade de consumo, marcada pelo "consumo de massas e para as massas, alta taxa de consumo e de descarte de mercadorias per capita, presença da moda, sociedade de mercado, sentimento permanente de insaciabilidade", a educação, como posto por Hegel (2010, p. 15) tem a tarefa de não apenas:

[...] tomar as medidas necessárias para que o desenvolvimento natural e espiritual transcorra, tanto quanto possível, sem entraves, mas, também, para que a vida individual e comunitária seja conduzida a sua mais elevada perfeição num discurso refletido, num pensamento penetrante e numa ação conforme à razão.

Sendo, então, por meio dela, que as presentes e futuras gerações poderão ter seus direitos assegurados, em especial os direitos a um meio ambiente ecologicamente equilibrado e à sadia qualidade de vida, buscando sempre o consumo controlado, ou seja, o consumerismo.

Um dos problemas sociais que essa forma de ciência gera é o consumismo, que, conforme Lyotard (1998), vive-se em um mundo onde tudo que é gerado deve ser consumido rapidamente para que assim novas produções surjam. Por um lado, isso é bom, pois impele o 
homem a criar e produzir cada vez mais, mas por outro é ruim, pois cria um estado de finitude existencial para o indivíduo, que busca a felicidade apenas no consumo momentâneo de bens. Além disso, quem fornece matéria-prima é o mundo, que passa ser explorado cada vez mais e sem limites.

Como destaca Gilles Lipovetsky, à medida que as sociedades enriquecem, surgem incessantemente novas vontades de consumir. Quanto mais se consome, mais se quer consumir. A época da abundância é inseparável de um alargamento indefinido da esfera das satisfações desejadas e de uma incapacidade de eliminar os apetites de consumo, sendo toda saturação de uma necessidade acompanhada imediatamente por novas procuras.

Já Zygmunt Bauman (2001) afirma que vivemos em uma modernidade líquida, que difere dos períodos anteriores em que havia solidez. O sólido é um corpo que é obrigado a ocupar determinado lugar no tempo e no espaço. Ele não pode estar aqui e ali ao mesmo tempo. O sólido representa as instituições da Idade Moderna. O sólido é a instituição fixada em um lugar, é limitada, de tal forma que o interesse é que as pessoas se situem dentro daquele espaço limitado para que assim sejam mais facilmente vigiadas e controladas.

Por exemplo, tradicionalmente a família se situava numa casa em um espaço, com todos os membros residindo no mesmo lugar. Porém, hoje a família é líquida, com a possibilidade de pais solteiros, filhos que fazem intercâmbio, bem como os meios de comunicação que tornam o contato quase que instantâneo. Logo, esta instituição não precisa mais estar agrupada, e isto a fortalece. Isso ocorre com todas as instituições, seja a família, a religião, o Estado, etc.

Assim, as instituições relativizam o espaço, o modo de ser e agir, o tempo, para que no fundo continuem fortalecidas. Seu modo é relativizado, mas a sua estrutura interna e propósito continuam intactos. Há então instituições líquidas que se retroalimentam. Hoje, são os próprios membros que cobram de seus participantes o atendimento às regras e valores morais daquela instituição. As instituições, junto com seus dogmas, existem ao mesmo tempo em todo lugar, o que torna ainda mais difícil a busca pela identidade individual do homem.

Bauman (2001) cita como grande exemplo os shoppings centers. Estes estabelecimentos oriundos da lógica capitalista não aceitam um contato profundo entre as pessoas, não é um espaço que as convida a visitar para interagirem entre si, mas apenas para o consumo. $\mathrm{O}$ importante é comprar no shopping center, não necessariamente manter ligações com outras pessoas. O shopping center tornou-se o templo do consumo, onde cada um cultua a própria individualidade como consumidor (BAUMAN, 2008).

Bauman afirma ainda que hoje predomina a superficialidade, a cultura do descartável. A realidade atual é bastante dinâmica, o que é moda hoje amanhã deixa de ser, o que é certo hoje amanhã está em dúvida. Há uma sensação constante de incerteza quanto ao futuro. Esta incerteza constante gera laços afetivos cada vez mais superficiais. Hoje as pessoas tendem a não ser profundas em seus relacionamentos, tanto afetivos como de trabalho, pois não há certeza que este relacionamento terá durabilidade (BAUMAN, 2001).

Os mecânicos de automóveis hoje não são treinados para consertar motores, mas apenas para retirar e jogar fora as peças usadas e defeituosas e substituí-las por novas. Dessa mesma forma ocorre na vida em geral, porque perder tempo com consertos que exigem trabalho se há a possibilidade de apenas jogar fora e trocar por algo novo. Como os compromissos de hoje são obstáculos para as oportunidades do amanhã, quanto mais leves e superficiais forem, menor o risco de prejuízos (BAUMAN, 2001).

Anthony Giddens (2002) nomeia a pós-modernidade como alta modernidade, pois para ele existe uma expansão das instituições que permeavam o período moderno. O homem, que antes tinha que conviver com sua cidade, sua região, agora precisa confrontar a cultura e as 
pessoas de toda a sociedade. Isto torna o homem muito mais vulnerável a se firmar em uma tendência ou identidade alheia.

A razão disto é que, diante de tantos modos de agir e pensar, o homem já não sabe mais qual o seu. Em uma busca por segurança, filia-se a uma causa, um modus operandi, etc. Da sociedade da forma que ela era está sofrendo uma passagem para uma sociedade global, na qual a Internet e tantos outros veículos de mídia instantaneamente comunicam pessoas de todas as partes do globo, difundindo estilos de vida, comportamentos e culturas.

Esta relação entre mídia e difusão de estilos de vida é particularmente enfática na questão do consumismo, que provoca a todos a seguirem os mesmos hábitos, comprarem as mesmas roupas, os mesmos alimentos, realizarem as mesmas diversões. Este modo de viver intensifica a massificação e favorece a perda da identidade, pois o indivíduo, ao ver que várias pessoas seguem determinado comportamento, decide também segui-lo.

Nesse contexto, Lipovetsky (2007) destaca que a ansiedade está por detrás do gosto dos jovens pelas marcas. A motivação que serve de base à aquisição de uma determinada marca não é tanto querer alçar-se acima dos outros, mas não parecer menos que os outros. É por isso que a sensibilidade às marcas é exibida tão ostensivamente nos meios desfavorecidos. Por uma marca apreciada, o jovem sai da impessoalidade, pretendendo mostrar não uma superioridade social, mas sua participação inteira e igual nos jogos da moda, da juventude e do consumo. O bilhete de entrada no modelo de vida da moda é o medo do desprezo e da rejeição ofensiva dos outros.

Além disso, como destaca Lipovetsky (2007), é possível interpretar a propensão a comprar como um novo ópio do povo, destinado a compensar o tédio do trabalho fragmentado, as falhas da mobilidade social, a infelicidade da solidão. Quanto mais o indivíduo está isolado ou frustrado, mais busca consolo nas felicidades imediatas da mercadoria. O consumo exerce sua influência apenas na medida em que tem a capacidade de aturdir e de adormecer, de oferecer-se como paliativo aos desejos frustrados do homem moderno.

A característica mais proeminente da sociedade de consumidores, ainda que cuidadosamente disfarçada e encoberta, é a "transformação dos consumidores em mercadorias" (BAUMAN, 2008, p. 20).

Importante o destaque de Lipovetsky (2007) que não é o consumismo como um todo que deve ser criticado, mas o seu excesso ou o seu imperialismo que constitui obstáculo ao desenvolvimento da diversidade das potencialidades humanas. A sociedade hipermercantil deve ser corrigida e enquadrada e não eliminada. Nem tudo é para ser rejeitado, muito é para ser reajustado e reequilibrado a fim de que a ordem tentacular do hiperconsumo não esmague a multiplicidade dos horizontes da vida.

\section{PERSONALIDADE, FELICIDADE E CONSUMO}

Além do estudo a partir da sociedade, outra forma de se estudar o fenômeno do consumismo é analisando a relação da personalidade do indivíduo com o consumo. Personalidade, de acordo com Davidoff (1983, p. 507), significa “[...] os padrões relativamente constantes e duradouros de perceber, pensar, sentir e comportar-se, os quais parecem dar às pessoas identidades separadas".

Tendo em vista a sociedade de consumo em que se vive, Erich Fromm (2008) destaca que a sociedade é devotada à aquisição de propriedade e obtenção de lucro, raramente se vê alguma evidência do modo de existência de ser, e a maioria das pessoas vê o ter como o modo mais natural da existência, até mesmo como o único modo aceitável de viver. Isso faz com 
que seja especialmente difícil para as pessoas compreenderem a natureza do ser, e até mesmo entender que ter é apenas uma orientação possível.

Fromm (2008) explana que houve uma mudança no modo de consumir. Antigamente, tudo que uma pessoa possuía ela apreciava, cuidava e usava até os limites de sua existência. Hoje, o consumo é enfatizado, não a preservação, e comprar se tornou um comprar e jogar fora. Seja o objeto um carro, um vestido, um aparelho, depois de usar um tempo, o indivíduo se cansa e está ansioso em se livrar do velho e comprar o modelo mais novo.

Para explicar a relação da personalidade do indivíduo com o que ele consome, Fromm (2008) usa o exemplo do carro próprio. Para quem tem um, o carro parece de uma necessidade vital, para aqueles que ainda não possuem um, o carro é um símbolo de alegria. Aparentemente, entretanto, a afeição pelo carro não é profunda e permanente, mas um caso de amor de curta duração, para os donos trocarem de carro com frequência, da procura até a compra, toda a transação parece um jogo, em que até mesmo a trapaça é, às vezes, um elemento principal, e um bom negócio é aproveitado tanto quanto, se não mais, que o prêmio final: um novo modelo na garagem.

Diversos fatores devem ser levados em consideração para entender essa relação. Primeiro, existe um elemento de despersonalização na relação do dono com o carro, o carro não é um objeto concreto que o dono gosta, mas é um símbolo de status, uma extensão de poder, um construtor de ego. Tendo comprado um carro, o dono na verdade adquiriu uma nova peça de ego. Um segundo fator é que comprando um novo carro, por exemplo, a cada dois anos em vez de seis, aumenta a emoção do comprador da aquisição, o ato de tornar um novo carro próprio é um tipo de defloração, aumenta a sensação de controle, e quanto mais acontece, maior é a emoção Fromm (2008).

O terceiro fator é que comprar carros frequentemente significa oportunidades de fazer um negócio, ganhar um proveito pela troca, uma satisfação profundamente enraizada em homens e mulheres da atualidade. O quarto fator é a necessidade de experimentar novos estímulos, porque os velhos estímulos estão esgotados depois de um pequeno tempo. O quinto fator reflete a mudança no caráter social que ocorreu nos últimos dois séculos, do caráter acumulador ao mercador Fromm (2008).

Thomas O'Guinn e Ronald Faber (1989) analisaram o fenômeno da compra compulsiva, identificando que os compradores compulsivos compram não para obter utilidade ou um serviço do bem comprado, mas para obter gratificação pelo processo de compra em si. A compra compulsiva serve principalmente para aliviar ansiedades e infelicidades.

O consumo compulsivo apresenta uma certa repetição e consumo excessivo que ocorre devido a ansiedade, depressão e tédio dos consumidores. Viciados em compras dependem do consumo excessivo da mesma maneira que um viciado busca drogas ou álcool, O'Guinn e Faber (1989).

O’Guinn e Faber (1989) conduziram uma pesquisa empírica, por meio de questionário, identificando alguns aspectos da personalidade dos compradores compulsivos. Eles identificaram que compradores compulsivos possuem baixa autoestima, como se sentir mau, culpado, pouco atraente, e sem uma clara identidade.

O problema do sentimento de identidade é descrevido por Erich Fromm como a própria condição da natureza humana e é fonte dos impulsos mais intensos. Assim, não se pode estar são sem o sentimento do eu, fazendo com que o indivíduo busque fazer quase qualquer coisa para adquiri-lo. Por detrás da forte paixão por um status ou situação e pela conformidade está essa mesma necessidade, que muitas vezes é mais forte que a necessidade de sobrevivência física, O’Guinn e Faber (1989). 
Compradores compulsivos também possuem um alto nível de fantasia/imaginação, assim, talvez em situações de compras esses indivíduos consigam focar ou refletir sobre seus pensamentos e sentimentos, conseguindo efetivamente escapar da realidade, O'Guinn e Faber (1989).

\begin{abstract}
Os compradores compulsivos não dão grande importância para a posse do item comprado, as gratificações derivam do contato interpessoal, emoções e positiva autoestima que foram geradas. Os itens comprados frequentemente tão pouca utilidade para o comprador e, em alguns casos, os produtos não são nem mesmo retirados da embalagem (O'GUINN; FABER 1989).
\end{abstract}

Analisando as consequências emocionais, O'Guinn e Faber (1989) identificaram compradores compulsivos frequentemente desenvolvem sentimentos de vergonha ou culpa associados com o seu comportamento. Sentimentos de alienação, problemas jurídicos e dificuldades no casamento também aparecem como consequências da compra compulsiva. Há ainda um forte sentimento de solidão e alienação das outras pessoas. Os compradores compulsivos frequentemente têm vergonha do seu comportamento e sentem que os outros não entenderiam e, às vezes, se descrevem como não amados e rejeitados por causa de seus comportamentos.

Uma das piores consequências seria o sentimento de frustração, de não ser capaz de controlar o próprio comportamento. Alguns compradores compulsivos descrevem o sentimento de ser incapaz de parar como extraordinariamente assustador e impossível para outros entenderem, O'Guinn e Faber (1989).

Pensamentos que emergem dentro do horizonte cognitivo moldado pelas práticas diárias dos consumidores invariavelmente acentuam o agudo interesse pelo mercado consumidor e ampliam-lhe os poderes de sedução. Ao contrário do processo produtivo, o consumo é uma atividade inteiramente individual. Ele também coloca os indivíduos em campos opostos, em que frequentemente se atacam. (BAUMAN, 1998).

Os "demônios interiores" desse tipo de sociedade nascem dos poderes de sedução do mercado consumidor. A Sociedade de consumidores não pode dispensar essa sedução mais do que a sociedade de produtores a podia dispensar, graças à vigência da regulamentação normativa. Por esta mesma razão, não pode permitir-se declarar guerra, menos ainda combater, à tendência do mercado de elevar os sonhos e desejos dos consumidores a um estado de frenesi e alçá-los às nuvens, por mais prejudicial que essa tendência possa revelar-se à forma de ordem em que se radica. E prejudicial à ordem ela o é, tanto quanto lhe é indispensável. (BAUMAN, 1998).

Os sentimentos de ansiedade e de solidão, que estão por detrás do comportamento consumista dos indivíduos, foram identificados como características do homem moderno por Rollo May (2009), que afirma que o principal problema do homem moderno é o vazio, é não saber o que quer e frequentemente não ter a mínima ideia do que sente.

O homem moderno fala muitas vezes daquilo que deveria querer, como conseguir um emprego, obter determinada titulação, apaixonar-se, casar-se e criar uma família, mas isso é uma mera descrição do que os outros (pais, professores, etc.) esperam que ele queira em vez do que ele realmente quer (MAY, 2009).

Esse sentimento de vazio acaba por gerar o sentimento de solidão. Quando uma pessoa não sabe com convicção o que ela quer ou sente, quando no período de uma mudança traumática, ela percebe que os desejos convencionais e objetivos que lhe foram ensinados não 
trazem nenhuma segurança ou dão qualquer senso de direção, ela sente um vazio interior, medo, e sua reação natural é procurar outras pessoas. Ela espera que os outros irão lhe dar um senso de direção ou pelo menos algum conforto na compreensão de que ela não está sozinha no seu medo. Assim, o sentimento de vazio e solidão são duas fases da mesma experiência básica de ansiedade Rollo May (2009).

Outra importante razão para o sentimento de solidão deriva do fato que a sociedade deposita grande ênfase na aceitação social. É o principal meio de aliviar a ansiedade e de obter prestígio. Assim, o indivíduo sempre deve provar que é um sucesso social sendo sempre procurado e nunca estando sozinho. O indivíduo retira muito da sua percepção da sua própria realidade daquilo que os outros dizem e pensam sobre ele, mas muitos homens modernos foram tão longe na sua dependência dos outros para os seus sentimentos de realidade que possuem medo que sem os outros eles perderiam o sentido da própria existência Rollo May (2009).

O consumo abundante é a marca do sucesso e a estrada que conduz diretamente ao aplauso público e à fama. Estimulando a possuir e consumir determinados objetos, e adotar certos estilos de vida, é a condição necessária para a felicidade, talvez até para a dignidade humana, esta é a sensação da maioria dos consumidores. Contudo, Bauman (2014) destaca em sua obra "cegueira moral a perda da sensibilidade na modernidade líquida" que a sociedade é tão influenciada pelo consumo e pelos desejos que, esquece-se da sua origem e do seu entorno; tornando-se insensível com o próximo e, consigo mesmo. Considerando que adoece a cada dia, na ânsia de conquistar mais e mais seu espaço e sobreviver na sociedade de consumo.

Na sequência são apresentadas algumas considerações sobre sustentabilidade, para que nas considerações finais a relação seja estabelecida. O foco será realizado na dimensão existencial da sustentabilidade, evidenciando que a gestão da pessoa acerca de si mesma e das relações com outros e ambientes é elemento indispensável para qualquer educação sustentável.

\section{IMPLICAÇÕES EXISTENCIAIS NA DIMENSÃO DA SUSTENTABILIDADE}

De acordo com a Comissão Mundial Sobre Meio Ambiente e Desenvolvimento (2001, p. 44) organizada pela Organização das Nações Unidas - ONU, "O desenvolvimento sustentável procura atender às necessidades e aspirações do presente sem comprometer a possibilidade de atendê-las no futuro". A sustentabilidade é uma dimensão da ética, algo que busca garantir a vida, é uma questão existencial.

Protágoras, sofista do século IV a. C., já dizia "O homem é a medida de todas as coisas [...] das coisas que são porque são, e das que não são porque não são.”. Em síntese, o mundo é entendido sempre na medida do homem. Vive-se tudo na medida do homem. Tudo que se conhece é relativo ao homem.

Seja qual for a área da vida a qual se direciona (educação, direito, engenharia, poesia, música, matemática, biologia, administração, etc.), seja qual for o objeto que se estude, no fundo, sempre se estará vendo a si mesmo, entendendo a si mesmo. Saber que tudo que se contata é em relação a si é o mesmo que dizer que, seja qual for a relação que se faz com o outro, se com profundidade entender este outro, chegará o ponto em que este outro desaparecerá e então será possível ver a si mesmo. Pois se em tudo que se contata é em relação a si, em tudo se encontra a si mesmo.

É essencial captar que o homem é um elemento que faz parte de um mundo, e que cada indivíduo constrói o seu próprio mundo, a partir de suas relações com as outras pessoas, objetos e o ambiente como um todo. Porém, na pós-modernidade, ocorre o que Frijot Capra 
chama de crise da percepção, caracterizada pelo pensamento estrito do materialismo-científico cominado com a compreensão separatista entre o indivíduo e o meio ambiente.

Para entender o conceito de sustentabilidade ético-existencial, é preciso entender o meio ambiente a partir do homem.

O homem é um filho da terra, dela ele se alimenta e em seu corpo reproduz, em modo sintético, a ordem deste planeta. Há uma continuidade complementar entre homem e planeta. O homem aperfeiçoa o ambiente para efetuar o próprio crescimento (VIDOR, 2008).

Se o homem desconhece a si mesmo, não administra a própria vida com saúde e não aperfeiçoa e realiza o próprio projeto, conforme o critério ético, ele não cumpre a dignidade de ser superior e ofende o próprio valor. Todo o erro praticado contra si mesmo repercute na ordem do ambiente onde ele vive (VIDOR, 2008).

O ambiente é uma extensão do organismo do homem e reflete a ordem e desordem de quem é responsável por zelar e regular-se pelas leis imanentes na própria natureza. Se o homem não resolve suas doenças e conflitos, fará o ambiente adoecer e, o ambiente devolverá ao homem as agressões que sofre (VIDOR, 2008).

O centro que irradia a desordem é o homem, é ele que projeta e amplifica no meio a desordem da própria vida individual e coletiva. Dele parte o medo da catástrofe, os anúncios que reforçam a angústia e as previsões menos animadoras. A agressão da dimensão não realizada em si próprio não lhe permite ver o ambiente como sua extensão.

Ao invés do homem cultivar o autoconhecimento para resolver seus males, ele insiste em forçar a adaptação social e então pela salvação da desordem que ele mesmo insemina no ambiente(VIDOR, 2008, p. 170).

A cultura e a ciência que o homem formalizou em base de uma consciência educada a olhar somente para o mundo externo, propiciou o avanço tecnológico, mas a insistência em adaptar o homem ao social manteve o homem em ignorância de si mesmo (VIDOR, 2008).

Nosso saber não necessita salvar e nem construir um novo planeta, mas precisa garantir um ambiente que não ofenda nem destrua a nossa vida. Sem compreender as regras da própria vida, sem saber ler todas as mensagens e depoimentos do próprio organismo, escritos por nossa alma inteligente, não saberemos organizar o ambiente sem que este ofenda a ordem do nosso corpo (VIDOR, 2008).

Ainda, contribui o mesmo autor;

O progresso tecnológico deve ser acompanhado de uma ciência humana mais evoluída. A objetividade só é alcançada na síntese compreensiva que anula a aparente separação entre sujeito e objeto, entre corpo individual e corpo ambiente, entre matéria e inteligência (VIDOR, 2008).

Para se entender de fato a relação entre ambiente e homem, é preciso primeiro entender a indissociabilidade entre sujeito e objeto, ou seja, compreender a vida como um sistema.

O problema é que o pensamento ocidental não percebe a unidade de todas as coisas, e sim opta-se por dividir o mundo em objetos e eventos isolados. É claro que essa divisão é necessária e útil para enfrentar o ambiente no dia a dia, porém não é uma característica fundamental da realidade, mas sim uma abstração elaborada pelo nosso intelecto afeito à discriminação e à categorização devido a falta de consciência e percepção dessa unidade (CAPRA, 2000) 
É essa situação que Capra define como crise da percepção, em que as pessoas e as grandes instituições sociais concordam com os conceitos de uma visão de mundo obsoleto, tendo uma percepção da realidade inadequada para lidar com um mundo superpovoado e globalmente interligado (CAPRA, 1996)

A vida humana é uma vida no mundo, e esse mundo existe para o homem, e se o homem age contra o mundo, mesmo assim age no mundo. Logo, é impossível isolar o homem (sujeito) do mundo (objeto), nem de fato, nem de conhecimento (KOJÊVÈ, 2002,).

Frijot Capra (1996) elucida que:

A própria física quântica mostra que não podemos decompor o mundo em unidades elementares que existam de maneira independente. Quando desvia-se a atenção dos objetos macroscópicos para as partículas subatômicas, o que se vê não é blocos de construção isolados e sim uma teia de relações entre as várias partes de um todo unificado.

Desde Newton os físicos tem acreditado que os fenômenos físicos podiam ser reduzidos às propriedades de partículas materiais rígidas e sólidas, no entanto, no década de 20 , a teoria quântica forçou-os a aceitar o fato de que os objetos materiais sólidos da física clássica se dissolvem, no nível subatômico, em padrões de probabilidade semelhantes a ondas (CAPRA, 1996)

Esses padrões não representam probabilidades de coisas, mas sim, probabilidades de interconexões. Sendo assim, as partículas subatômicas não são coisas, mas interconexão entre coisas, que por sua vez são interconexões de outras coisas, e assim por diante, nunca chegando a nenhuma coisa, apenas interconexões (CAPRA, 1996).

Todo e qualquer organismo é uma totalidade integrada e, portanto, um sistema vivo, desde a menor bactéria, passando pelas plantas e animais, até os seres humanos. No corpo de um ser humano, por exemplo, as células e os tecidos são sistemas vivos, sendo o cérebro o exemplo mais complexo. Porém, os sistemas não se resumem a organismos individuais e suas partes, os mesmo aspectos de totalidade são exibidos em sistemas sociais, como um formigueiro e uma colmeia no mundo animal e o núcleo familiar nos seres humanos, e em ecossistemas que consistem em uma grande variedade de organismos e até mesmo de matéria inanimada em interação mútua. A preservação de uma área selvagem não é de árvores ou espécies de animais, mas de toda uma complexa teia de relações entre eles (CAPRA, 2007).

Um exemplo dessa complexa teia de relações é fornecida por Margulis e Sagan (2002):

Todos os organismos levam vidas múltiplas. A bactéria cuida de suas próprias necessidades na lama de um charco salgado, mas também molda o ambiente e altera a atmosfera. Como um membro da comunidade, retira os dejetos de um vizinho e gera o alimento de outro. $\mathrm{O}$ fungo cuida de sua vida em meio aos detritos florestais, enquanto perfura a folha de uma árvore próxima e ajuda a fechar o círculo do fluxo biosférico do fósforo.

Todos os sistemas naturais são totalidades cujas estruturas específicas resultam das interações e interdependência de suas partes. As atividades dos sistemas naturais envolvem uma interação simultânea e mutuamente interdependente entre seus diversos componentes, as propriedades sistêmicas são destruídas quando um sistema é dissecado, física ou teoricamente, em elementos isolados. Embora se possa discernir as partes individuais de um sistema, a natureza do todo é sempre diferente da simples união de partes separadas (CAPRA, 2007) 
Maturana (2006, p. 177) destaca que o meio, enquanto espaço no qual um sistema funciona como um todo tem:

\begin{abstract}
Uma dinâmica estrutural independente da dinâmica estrutural dos sistemas que ele contêm, apesar de ser modulado pelos seus encontros com eles. Portanto, o meio e os sistemas que ele contém estão em mudanças estruturais contínuas, cada uma de acordo com sua própria dinâmica estrutural e cada um modulado conforme as mudanças estruturais que causam um no outro através de seus encontros.
\end{abstract}

Resumindo: todo ser vivo existe como um sistema dinâmico em contínua mudança estrutural, o modo de viver que define uma espécie, uma linhagem, ou um sistema de linhagem, se dá em uma dinâmica de relações entre o homem e o meio (MATURANA, 1998).

As propriedades das partes não são intrínsecas, mas só podem ser entendidas dentro do contexto do todo mais amplo. Por isso que quando se fala em ecologia de forma profunda não se fala em uma coleção de objetos isolados, mas sim de uma rede de fenômenos que estão interconectados e interdependentes, reconhecendo assim o valor intrínseco de todos os seres vivos, concebendo os seres humanos apenas como um fio particular na teia da vida CAPRA, 1996).

Michel Maffesoli (1998) fala que o eu, o objeto do conhecimento e o próprio conhecimento fazem um só corpo, numa perspectiva holística que parece a mais adequada para perceber a estreita ambição dos diversos elementos da sociedade complexa. A consciência de si, o meio natural e o social onde se está situado, e a compreensão do conjunto estão organicamente ligados. É tal inserção que permite uma visão de dentro, essa intuição reprimida pela modernidade.

Conforme aduz Antonia Ferreira Nonata (2007), é lamentável que os líderes políticos, administradores e até mesmo os professores das grandes universidades, não reconheçam essa realidade. Isso evidencia a necessidade urgente de mudança da percepção da realidade, marcada pela compreensão de que os problemas que a sociedade vivencia são sistêmicos, interligados e interdependentes.

A sustentabilidade, portanto, não pode iniciar com políticas públicas e diretrizes jurídicas, antes depende de impostação existencial. Enquanto a contemporaneidade seguir enfatizando o vínculo entre Felicidade e Consumerismo a tendência será sempre a organização dos estilos de vida direcionados à busca pela felicidade preponderantemente na dimensão do consumo. E isto provoca impactos nas questões da sustentabilidade. Portanto, antes da política e do direito há a necessidade de mudança cultural das sociedades contemporâneas. A proteção à biodiversidade, aos ecossistemas, às reservas de águas, o enfrentamento da crescente poluição e dos problemas de aquecimento global, dependem antes de uma pedagogia existencial de responsabilização humana diante de si e do mundo, enfatizando que a felicidade é uma realização diária dos próprios projetos e não o consumo irracional dos recursos disponíveis.

\title{
5 CONSIDERAÇÕES FINAIS
}

A sociedade de consumo vem provocando um comportamento generalizado e, ao mesmo tempo, individualizado de consumo desmedido e impensado, alcançando a exasperação da moda a uma alta taxa de descarte de mercadorias. A obsolescência programada, quando o fabricante planeja "o envelhecimento de um produto", ou seja, programa "quando determinado objeto vai deixar de ser útil e parar de funcionar, apenas para aumentar o consumo" é apenas um exemplo das estratégias para garantir a compra constante de bens que movimenta o mercado. 
O consumidor não está mais atento à qualidade e durabilidade do produto que consome, ele o adquire, como visto anteriormente, com o objetivo de satisfazer seus desejos. Assim, verifica-se a clara transição entre a sociedade tradicional para a sociedade de consumo. A insatisfação dos desejos instáveis e rapidamente mutáveis do consumidor o leva a descartar os objetos que comprou com a promessa de cumprir esta tarefa. Vê-se como, com apenas uma única situação ocasionada pela cultura do consumo, o meio ambiente e os direitos dos indivíduos são comprometidos. É pela alta taxa de desperdício, e pela decrescente distancia temporal entre o brotar e o murchar do desejo, que o fetichismo da subjetividade se mantém vivo e digno de crédito, apesar da interminável série de desapontamentos que ele causa. A sociedade de consumidores é impensável sem uma florescente indústria de remoção do lixo. Não se espera dos consumidores que jurem lealdade aos objetos que obtêm com a intenção de consumir. (BAUMAN, 2008).

A insaciabilidade dos desejos supérfluos do homem contemporâneo aqui gera toneladas de lixo que devem ser removidas e que muitas vezes não tem a destinação adequada, acarretando enorme ônus ao planeta e a todas as espécies. Assim, é possível constatar, que, como já destacado por Fritjof Capra, tudo está relacionado e cada ação tem uma reação, que o homem vive em uma grande teia.

Diante das inúmeras projeções e conceitos distorcidos pelo ser humano, é elementar a tomada de consciência do lugar que ele ocupa no planeta para que não se deixe influenciar pelas culturas insustentáveis e consumistas e venha a prejudicar o meio ambiente e as futuras gerações:

A sustentabilidade, portanto, não pode iniciar com políticas públicas e diretrizes jurídicas, antes depende de impostação existencial. Enquanto a contemporaneidade seguir enfatizando o vínculo entre Felicidade e Consumerismo a tendência será sempre a organização dos estilos de vida direcionados à busca pela felicidade preponderantemente na dimensão do consumo. E isto provoca impactos nas questões da sustentabilidade. Portanto, antes da política e do direito há a necessidade de mudança cultural das sociedades contemporâneas. A proteção à biodiversidade, aos ecossistemas, às reservas de águas, o enfrentamento da crescente poluição e dos problemas de aquecimento global, dependem antes de uma pedagogia existencial de responsabilização humana diante de si e do mundo, enfatizando que a felicidade é uma realização diária dos próprios projetos e não o consumo irracional dos recursos disponíveis.

\section{REFERÊNCIAS}

BARBOSA, Livia. Sociedade de consumo. Rio de Janeiro: Jorge Zahar Editor, 2004.

BAUMAN, Zygmunt. O Mal-Estar da Pós -Modernidade. Rio de Janeiro: Jorge Zahar, 1998.

Modernidade Líquida. Rio de Janeiro: Jorge Zahar, 2001.

. Vida para o consumo: a transformação das pessoas em mercadorias. Rio de Janeiro: Jorge Zahar, 2008.

. Cegueira Moral; a perda da sensibilidade na modernidade líquida. Rio de Janeiro: Jorge Zahar, 2014.

BOFF, Leonardo. Sustentabilidade: o que é - o que não é. Petrópolis: Vozes, 2012. 
CAPRA, Fritjof. A Teia da Vida: Uma Nova Compreensão Científica dos Sistemas Vivos. São Paulo: Cultrix, 1996.

O Ponto de Mutação: A Ciência, a Sociedade e a Cultura emergente. 28. ed. São Paulo: Cultrix, 2007.

Teia da vida: Uma nova compreensão cientifica dos sistemas. Tradução de Newton Roberval Eichemberg. São Paulo: Editora Cultrix. 2010.

COMISSÃO MUNDIAL SOBRE MEIO AMBIENTE E DESENVOLVIMENTO. Nosso Futuro Comum. 2. ed. Rio de Janeiro: FGV, 2001.

DAVIDOFF, Linda. Introdução à psicologia. São Paulo: McGraw-Hill, 1983.

FIRAT et al. Consumption, Consumer Culture and Consumer Society. Journal of Community Positive Practices, Bucharest, v. 13, n. 1, p. 182-203, 2013.

FROMM, Erich. To Have or to Be? London; New York: Continuum, 2008.

FROMM, Erich. Psicoanálisis de la sociedad contemporánea. 6. ed. Ciudad de México: Fondo de Cultura Economica, 1964.

GIDDENS, Anthony. Modernidade e Identidade. Rio de Janeiro: Jorge Zahar, 2002.

KOJÈVÈ, Alexandre. Introdução à leitura de Hegel. Rio de Janeiro: Universidade Estadual do Rio de Janeiro, 2002.

LIPOVETSKY, Gilles. A Felicidade Paradoxal: ensaio sobre a sociedade de hiperconsumo. 2007

MARGULIS, Lynn; SAGAN, Dorion. O que é vida? Rio de Janeiro: Jorge Zahar, 2002.

MAFFESOLI, Michel. Elogio da Razão Sensível. Petrópolis: Vozes, 1998.

MATURANA, Humberto. Cognição, Ciência e Vida Cotidiana. Belo Horizonte: UFMG, 2006.

MAY, Rollo. Man's Search For Himself. New York; London: W. W. Norton \& Company, 2009.

NONATA, Antonia Ferreira. Paradigmas do Conhecimento: do moderno ao ecológico. Diálogo Educ., Curitiba, v. 7, n. 22, p. 259-275, set./dez. 2007. Disponível em: <http://www2.pucpr.br/ reol/index.php/DIALOGO?dd1=1587\&dd99=pdf>. Acesso em: 07 jun. 2012.

O'GUINN, Thomas C.; FABER, Ronald J. Compulsive Buying: A Phenomenological Exploration. Journal of Consumer Research, Chicago, v. 16, n. 2, p. 147-157, set. 1989. 
PLEINES, Jürgen-Eckardt. Friedrich Hegel. Tradução e organização de Sílvio Rosa Filho. Recife: Fundação Joaquim Nabuco, Editora Massangana, 2010. Disponível em: <http://www. dominiopublico.gov.br/download/texto/me4671.pdf>. Acesso em: 16 maio 2018. p.15.

SOËTARD, Michel. Jean-Jacques Rousseau. Tradução de Verone Lane Rodrigues. Recife: Fundação Joaquim Nabuco, Editora Massangana, 2010. Disponível em: <http://www. dominiopublico.gov.br/download/texto/me4675.pdf>. Acesso em: 16 maio 2018. p.14.

VIDOR, Alecio. Filosofia Elementar. IESDE: Curitiba, 2008. 